\title{
MGMT Promoter Methylation Testing Method
}

National Cancer Institute

\section{Source}

National Cancer Institute. MGMT Promoter Methylation Testing Method. NCI

Thesaurus. Code C158919.

A request to enter the specific molecular analysis method used to detect the methylation of promoter sequences of the MGMT gene. 